\author{
M. Ashok Kumar ${ }^{\mathrm{a}, 1}$, A.M.K. Prasad ${ }^{\mathrm{b}}$, D.V. Ravishankar ${ }^{\mathrm{c}}$, G. Giridhar ${ }^{\mathrm{d}}$ \\ ${ }^{a}$ Vignan Institute of Technology \& Science, Dept. of Mech. Eng., Hyderabad, Telangana, India \\ ${ }^{b}$ UCE, Osmania University, Dept. of Mech. Eng., Hyderabad, Telangana, India \\ ${ }^{c}$ TKR College of Engineering, Dept. of Mech. Eng., Hyderabad, Telangana, India \\ ${ }^{d}$ Vignan Institute of Technology \& Science, Dept. of Mech. Eng., Hyderabad, Telangana, India \\ 1mak864@rediffmail.com
}

\title{
CHARACTERIZATION OF COMPOSITE LAMINATES SUBJECTED TO REPEATED INDENTATION
}

\begin{abstract}
The effect of the fiber orientation in a laminate is investigated experimentally when subjected repeated quasistatic indentation. All the laminates with different fiber orientation are subjected to indentation with a stainless steel spherical indenter of diameter $8.0 \mathrm{~mm}$ on a universal testing machine for a maximum indenter displacement of $4 \mathrm{~mm}$. The rate of indenter displacement was $0.5 \mathrm{~mm} / \mathrm{minute}$. Different parameters like load bearing capacity, indentation diameter, area of surface damage, etc., were recorded after $4 \mathrm{~mm}$ of indenter displacement. All the parameters were studied and compared to evaluate the laminate with high strength.
\end{abstract}

Key words: epoxy resin, e-glass fiber, laminate, indentation, delamination

\section{INTRODUCTION}

It has been increasing enormously at present; the usage of composite materials in the areas of automotive, aerospace, defense and in sports industries and in many more applications. Composite materials have many advantages over conventional materials because of their superior properties like strength to weight ratio, stiffness to weight ratio, non-corrosive properties, resistance to climatic conditions, high fatigue life, product cost etc., The fiber/matrix interface is known to play a major role in the mechanical performance of fiberreinforced composites. This contribution is mainly related to the ability of the interface to transfer the mechanical load from matrix to fiber during loading. Researchers in this field have found that this stress-transfer process affects some quasi-static properties such as the strength. However, the importance of the interface becomes largely predominant in the overall behavior of the composite. The composite structures may get damage during manufacturing, maintenance works and during their service. They may be subjected to low velocity impact by the tools also. This local impact is likely to cause damage locally and induce degradation in their strength. The size and type of damage will depends on various parameters like geometries of the support, projectile diameter, size, shape and angle of impact. Extensive studies are taking place concerning the foreign object damage response of composite materials structures. It also observed that low energy impact loading is very important for the laminated composite structures. In such composites, impact induces an internal damage that cannot be detected by a visual inspection but can cause noticeable reduction in strength. It was found that the damage in composite laminate due to quasi-static 
indentation, which is similar to the low velocity impact, hence it allows using quasi-static indentation tests in order to analyze the impact damage mechanisms. Earlier experimental studies have taken place to characterize the damage due to indentation. Damage zone remains localized beneath the indenter as the tri-dimensional fiber architecture prevents delamination. The aim of this research work is to investigate the influence of fiber angle in the damage of composite laminate, subjected to quasi-static indentation. Damage in the composite laminates results from the interaction between different failure mechanism like matrix cracking, fibermatrix debonding, delamination between the successive layers and fiber breakage. However in quasi-static indentation mostly the damage may result due to delamination between the layers. For this purpose, static tests were conducted on the composite laminate loaded at the centre by a spherical stainless steel indenter. All the tests were stopped at fixed values of the indenter displacement. Composite laminates with different fiber angles were supported on a square frame. The intensity of the damage caused is observed by the optical light microscope. Ross and Sierakowski[1] studied the effects of impacts exerted by conical head impactor and observed delamination in glass epoxy plates by using a powerful light source. Low energy impact loading is an important for polymer matrix composites in which impact induces an internal damage which may not be detected by a visual inspection and many cause a noticeable strength reduction. It is experimentally proved that damage in polymer matrix composite due to quasi-static indentation is similar to that of low velocity impact loading [2]. Specific damages in highly oriented plates along the longitudinal direction formed with two different layers, woven fabric and quasi UD, have been observed. It consists of the development of matrix cracks, starting from non-impacted side, which develop in a conical form through the thickness of the specimen. A comparison between static and dynamic tests was treated. The maximum force attained during the impact tests is greater than the one during the quasi-static tests. The absorbed energy and damage morphology are equivalent for both tests [3].Failure at the interface is modeled by degrading stresses using two interface damage parameters corresponding to interfacial tension and shear failure, while fracture mechanics concepts are introduced by relating the total energy absorbed in the damaging process to the interfacial fracture energy [4].These authors are studying the behavior of composite structures at low-velocity impact. They are trying to give explanation and to simulate the different damage phenomena observed during the experimentation more studies are still required to have better understanding of the damage phenomena developed in these structures during the impact [5-7]. A simple power law equation was assessed, correlating the dent depth with impact energy. It was shown that, if the ratio of the impact energy to the penetration energy is adopted as the independent parameters, the relationship proposed is negligibly affected by the laminate type and thickness [8]. The experimental results demonstrate that the penetration energy is substantially unaffected by the loading speed, so that the formula proposed by these authors for the evaluation of the penetration energy is also effective in static tests [9-10]. Freitas et al [11] have carried out a numerical study to examine the failure mechanisms in composite specimens subjected to impact loading. Results show that the numerical evaluation of impact with a linear static finite element analysis is not very accurate, but it gives meaningful insights on the major mechanisms of failure. Metals show visible damage caused by impact mainly on the surface of the structures, but for composites the damage is hidden inside the member when subjected to low velocity impact [12]. Wu and Chang [13] studied ballistic impact response of monolithic fibers reinforced composite laminates, where they found that the contact force is dependent on the mass of the projectile, but it has no influence on the amount of the absorbed energy, which is found to be dependent on the initial energy of the impactor. While Zhou and Greaves studied damage resistance and tolerance of glass fiber reinforced plates with different thickness [14]. The aim of this paper is 
to study the influence of e- glass powder percentages and the effect of indenter rate of loading on the e-glass / epoxy composite laminate with different fiber orientation.

\section{EXPERIMENTAL PROCEDURE}

The composite laminates with E-glass fiber/epoxy are fabricated with different fiber orientation. All the laminates are subjected to indentation with a stainless steel spherical indenter of diameter $8.0 \mathrm{~mm}$ on a universal testing machine for a repeated indenter displacement of $4 \mathrm{~mm}$ for three times with a rate of indenter displacement $0.5 \mathrm{~mm} / \mathrm{minute}$.

\section{RESULTS AND DISCUSSIONS}

The Top and Bottom laminates after indentation are shown in figures 1, 3, 5, 7, 9, 11, 13.

\section{Specimen with Fiber orientation $\left(0^{0} / 15^{0}\right)$}

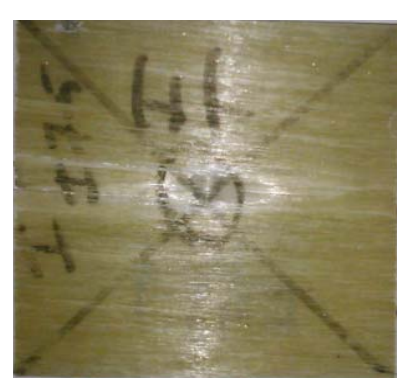

Top view

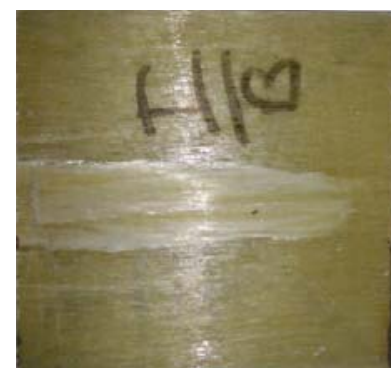

Bottom view

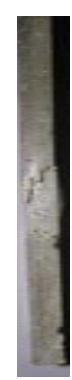

Side view

Fig. 1. Laminate after indentation $\left(0^{0} / 15^{0}\right)$

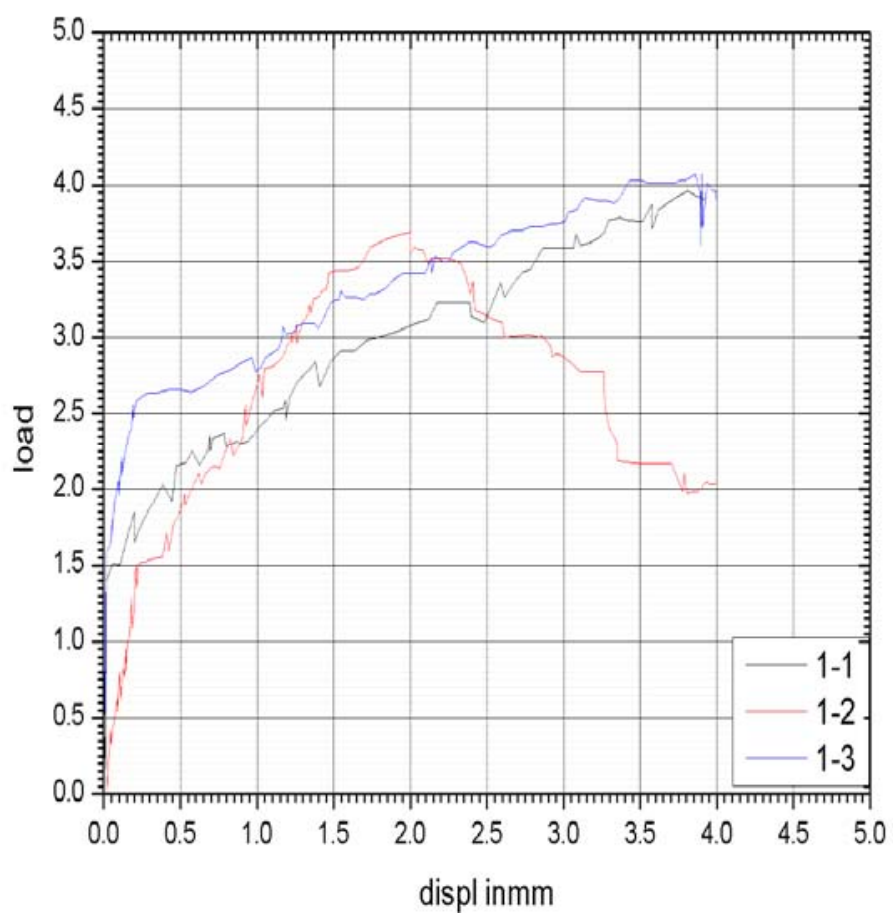

Fig. 2. Load vs. displacement (1-1 loading, 1-2 first reloading, 1-3 second reloading) 
When the laminates are transversely loaded with steel ball indenter in the first time (1-1 curve) up to $4 \mathrm{~mm}$ it is found that stiffness of the laminate is very high a maximum load recorded is $4 \mathrm{kN}$ at a displacement of $4 \mathrm{~mm}$. When the laminate loaded for second time (1-2 curve), there is an appreciable decrease in the stiffness of the laminate. The maximum load observed as $3.6 \mathrm{kN}$ at a displacement of $1.8 \mathrm{~mm}$. Kinks are observed due to the failure of matrix and fibre alternately and the load is reduced to $2 \mathrm{KN}$ at a displacement of $4 \mathrm{~mm}$. when the specimen was reloaded for third time (1-3 curve) it is observed that the maximum load reached was 4 at an indenter displacement of $4 \mathrm{~mm}$ as shown in fig. 2.

Specimen with Fiber orientation $\left(0^{\circ} / 30^{\circ}\right)$

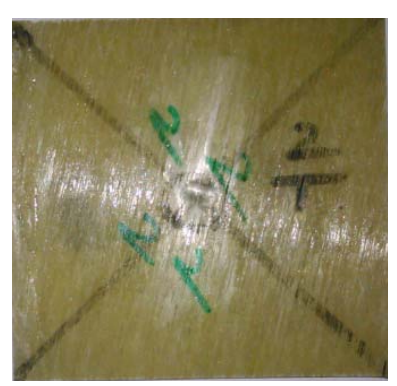

Top view
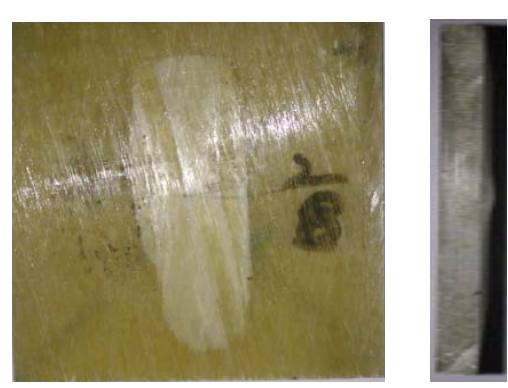

Bottom view

Side view

Fig. 3. Laminate after indentation $\left(0^{\circ} / 30^{\circ}\right)$

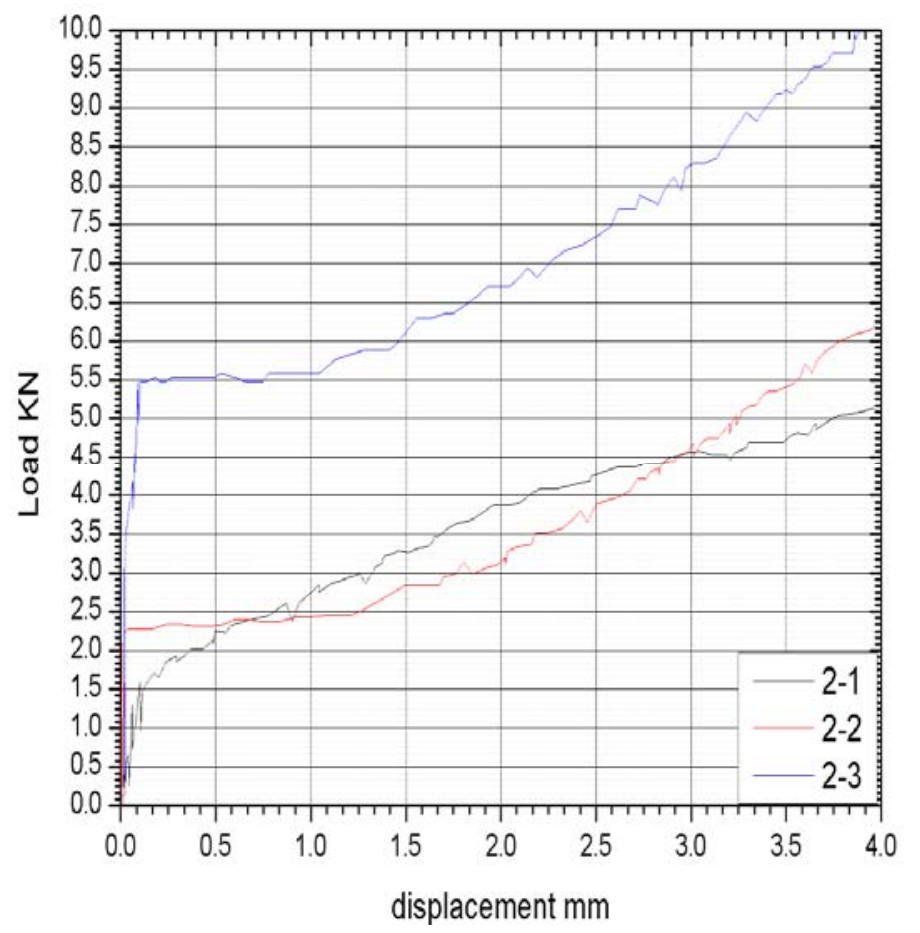

Fig. 4. Load vs. displacement (2-1 loading, 2-2 first reloading, 2-3 second reloading) 
Many kinks are observed during beginning of the loading on the specimen, and the laminate is weak in the beginning, however the load is proportionally increased (2-1 curve) till the end of $4 \mathrm{~mm}$ indenter displacement with a maximum load of $10.0 \mathrm{kN}$. There is no indentation dent during first loading. When the laminate is loaded for the second time (2-2 curve), there is an increase in the stiffness up to $1.3 \mathrm{~mm}$ indenter displacement with a consistent load of $2.3 \mathrm{kN}$. After $1.3 \mathrm{~mm}$ indenter displacement there is gradual increase in load( maximum load of $6.3 \mathrm{kN}$ ) at a displacement of $4 \mathrm{~mm}$ with an indentation depth of $1.3 \mathrm{~mm}$. It is also observed that there is no deflection of laminate. When the specimen is loaded for third time (2-3 curve) there is an enormous increase in stiffness with a load of 6.3kN.as shown in fig. 4.

\section{Specimen with Fiber orientation $\left(0^{0} / 45^{0}\right)$}

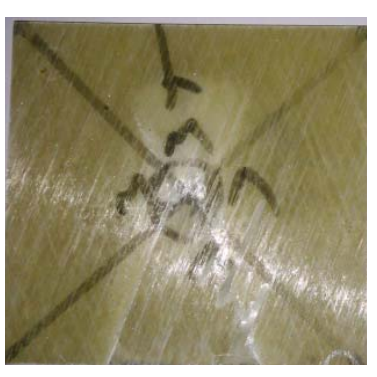

Top view
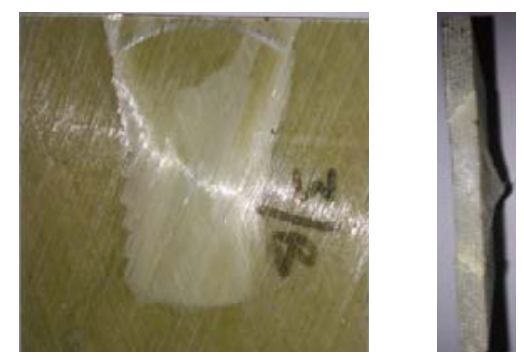

Bottom view

Side view

Fig. 5. Laminate after indentation $\left(0^{\circ} / 45^{0}\right)$

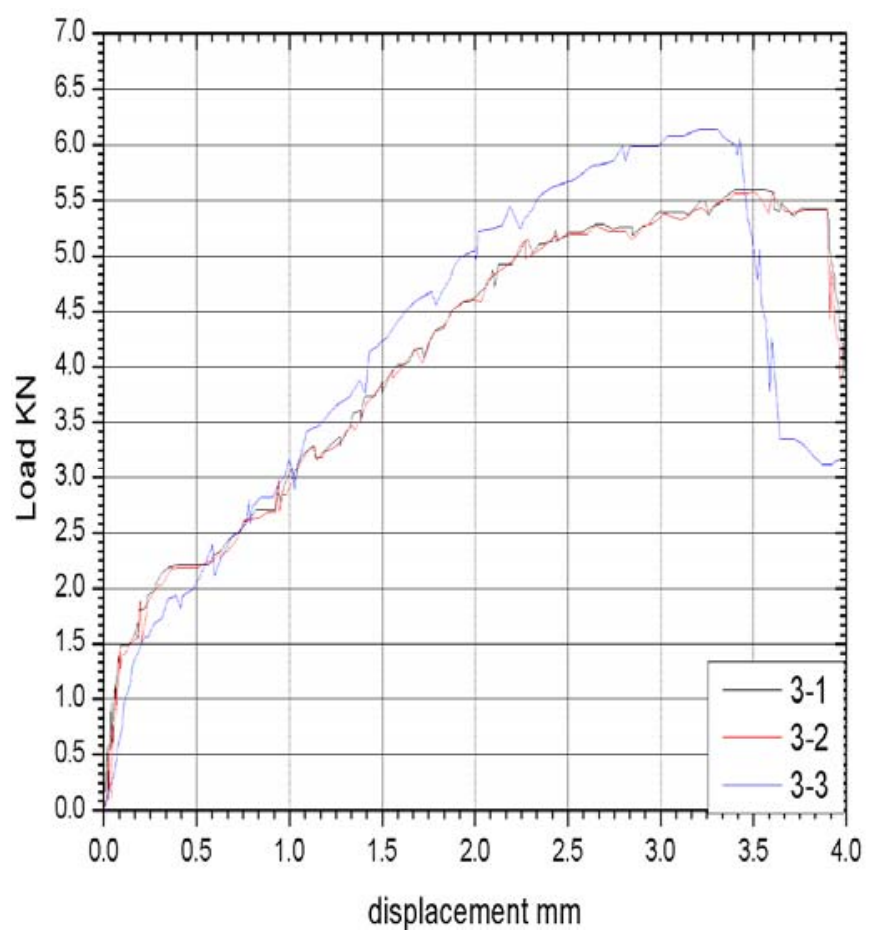

Fig. 6. Load vs. displacement (3-1 loading, 3-2 first reloading, 3-3 second reloading) 
The stiffness of the laminate is almost same in all the three loadings. The load-displacement curves for first two loadings (3-1, 3-2 curves ) are similar and also no degradation in the stiffness for first two loadings as shown in Fig. 6. But during the second reloading (3-3 curve) the stiffness reduced. It followed the same trend in the curve up to a displacement of $2 \mathrm{~mm}$. Later there is a little increase in the load (maximum load of $5.6 \mathrm{kN}$ ) at a displacement of $3.6 \mathrm{~mm}$ and $5.7 \mathrm{kN}$ for first reloading and $6.1 \mathrm{kN}$ for second reloading at a displacement of $3.1 \mathrm{~mm}$ respectively as shown in fig. 6 .

\section{Specimen with Fiber orientation $\left(0^{\circ} / 60^{\circ}\right)$}

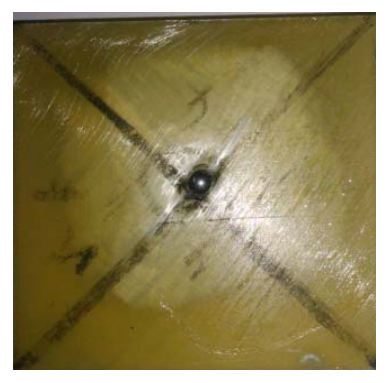

Top view

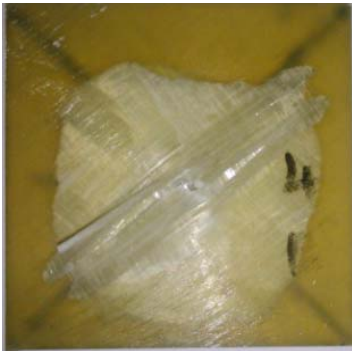

Bottom view

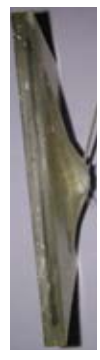

Side view

Fig. 7. Laminates after indentation $\left(0^{\circ} / 60^{\circ}\right)$

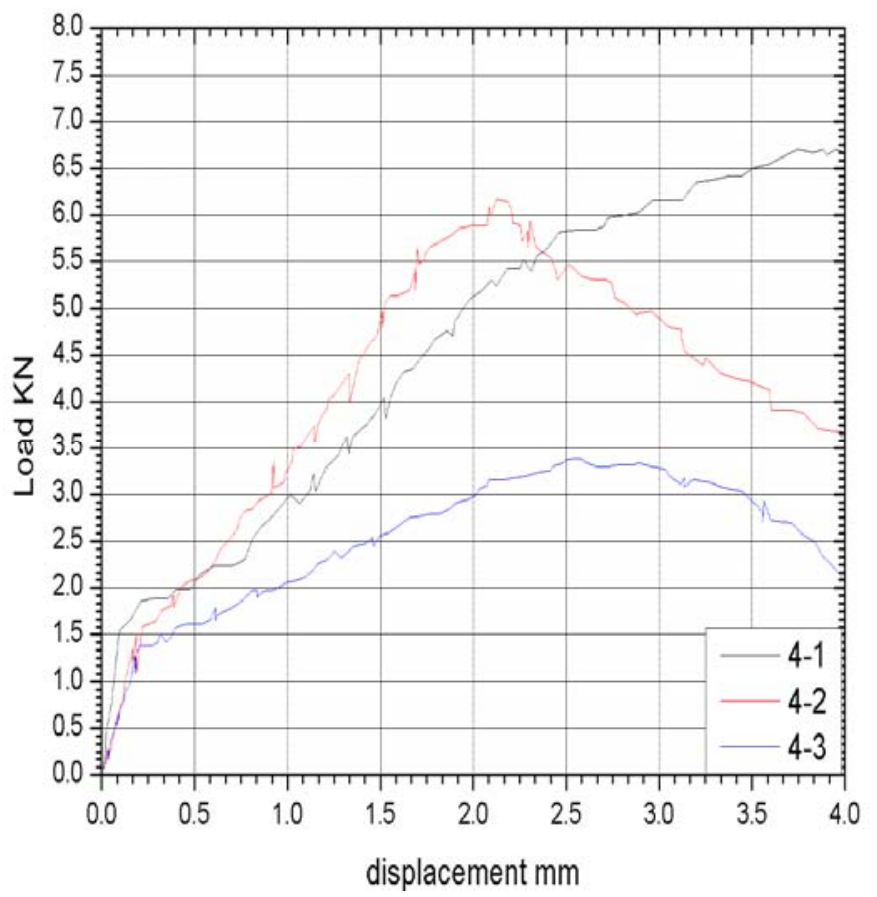

Fig. 8. Load vs. displacement (4-1 loading, 4-2 first reloading, 4-3 second reloading) 
There is a gradual reduction in stiffness during loading(4-1) and reloading(4-2). For the first two loadings the maximum load attained at $2 \mathrm{~mm}$ displacement is recorded as $6.8 \mathrm{kN}$ and $6.1 \mathrm{kN}$ respectively. But for second reloading(4-3) there is degradation in the strength and shown a maximum load of $3.4 \mathrm{kN}$ at $2.4 \mathrm{~mm}$ displacement as shown in fig. 8 .

\section{Specimen with Fiber orientation $\left(0^{0} / 90^{0}\right)$}

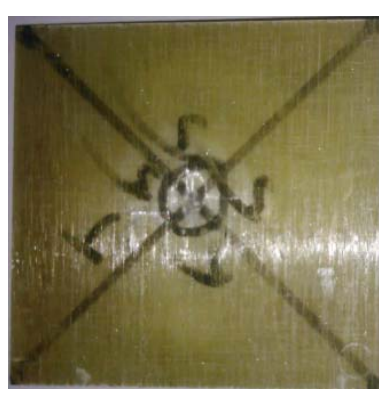

Top view

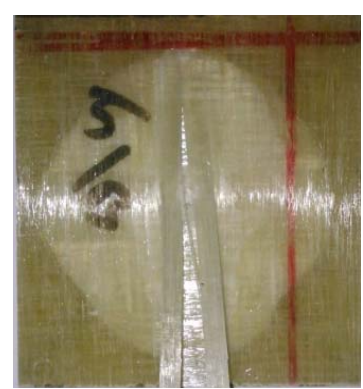

Bottom view

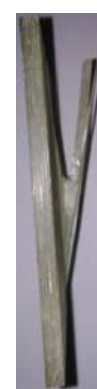

Side view

Fig. 9. Laminates after indentation $\left(0^{\circ} / 90^{\circ}\right)$

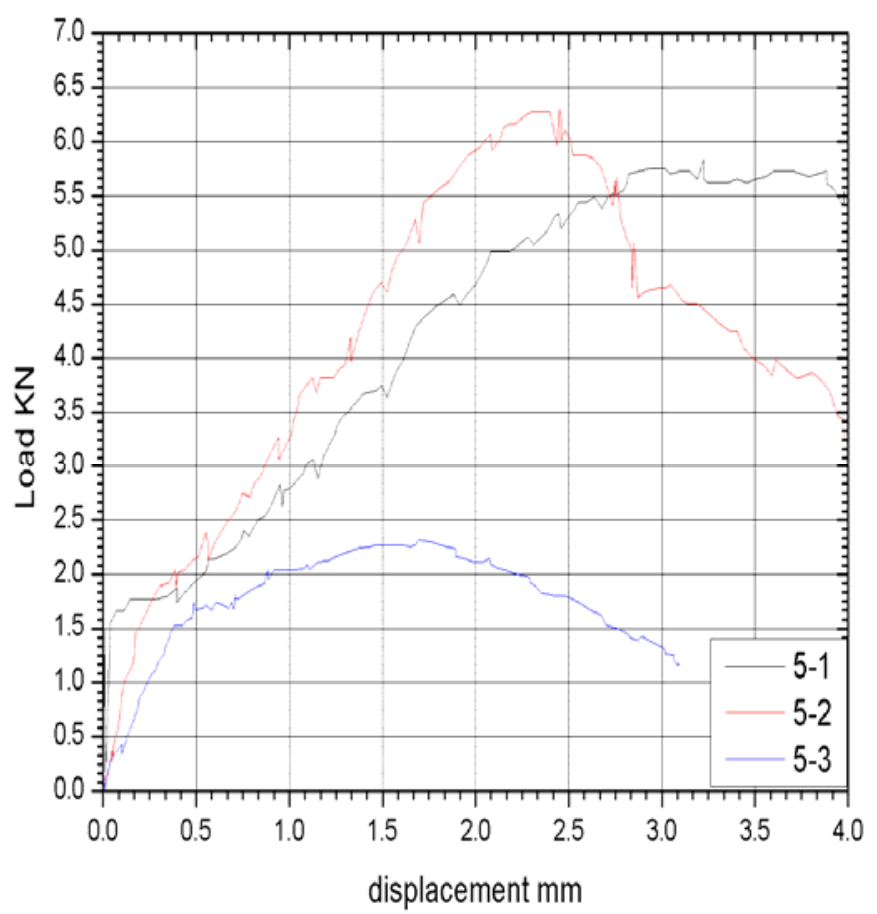

Fig. 10. Load vs. displacement (5-1 loading, 5-2 first reloading, 5-3 second reloading) 
It is observed that the laminate stiffness is same up to a load of $1.5 \mathrm{kN}$ and thereafter deflection of the laminate began. The load proportionally increased up to a displacement of $2.8 \mathrm{~mm}$ for first (5-1 curve) with a maximum load of $5.7 \mathrm{kN}$ and a maximum load of $6.2 \mathrm{kN}$ (5-2 curve) for the first reloading at a displacement of $2.2 \mathrm{~mm}$, immediately afterwards damage in the specimen occurred. When the specimen is reloaded second time (5-3 curve) the specimen degraded in strength and occurred damage which led to low load of $2.3 \mathrm{kN}$ only and thereafter degradation started as shown in fig. 10.

\section{Specimen with Fiber orientation $\left(+/-45^{0}, 0^{0}\right)$}

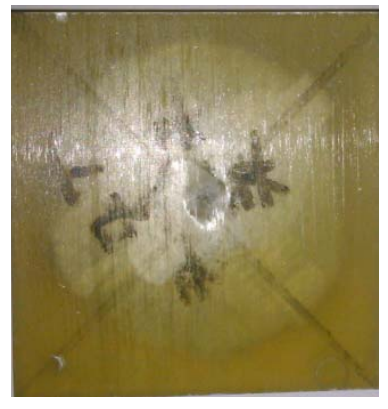

Top view
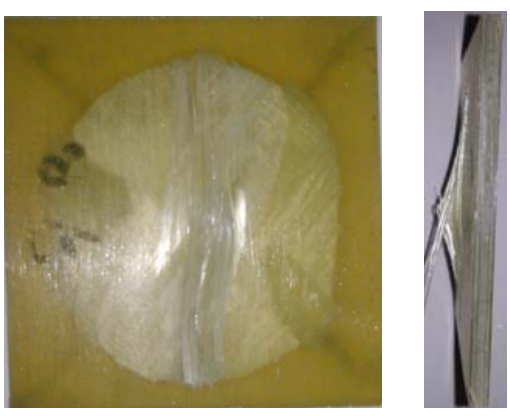

Bottom view

Side view

Fig. 11. Laminates after indentation $\left(+/-45^{\circ}, 0^{\circ}\right)$

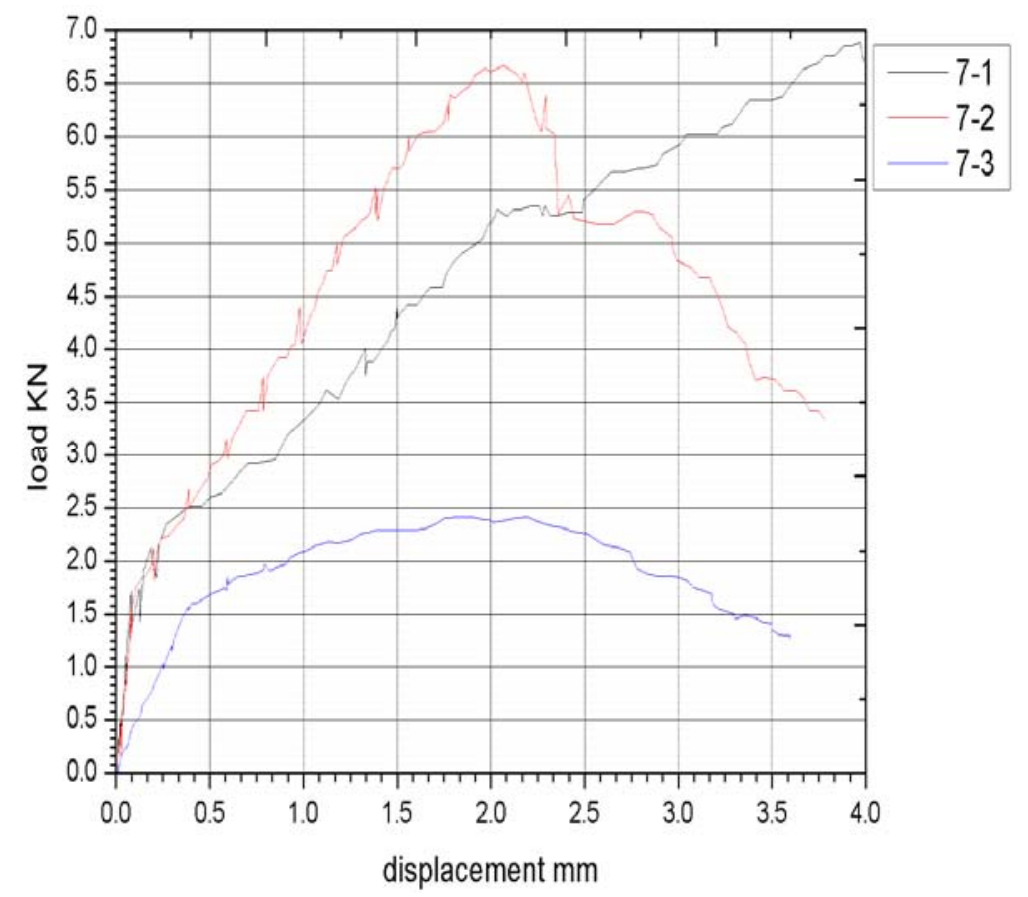

Fig. 12. Load vs. displacement (7-1 loading, 7-2 first reloading, 7-3 second reloading) 
The global stiffness of specimen remained unchanged for first two loadings. When the specimen is loaded there is an increase in the load proportional to the displacement of the indenter with a maximum load (7-1 curve) at a displacement of $4 \mathrm{~mm}$. When the specimen was first reloaded (7-2 curve) then load is a increased suddenly with the indenter displacement and found maximum load at a displacement of $2.2 \mathrm{~mm}$ and sudden decrease in the load. When the specimen is second time reloaded (7-3 curve), the stiffness is further reduced and the maximum load is only $2.4 \mathrm{KN}$ at a displacement of $2 \mathrm{~mm}$ as shown in fig. 12 .

\section{Specimen with Fiber orientation $\left(+/-45^{\circ}, 90^{\circ}\right)$}

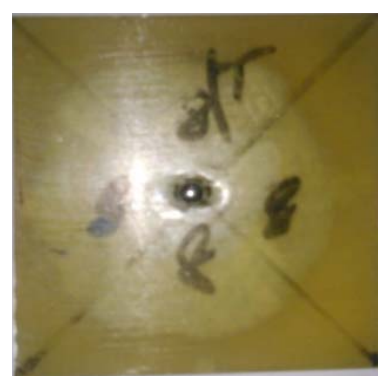

Top view
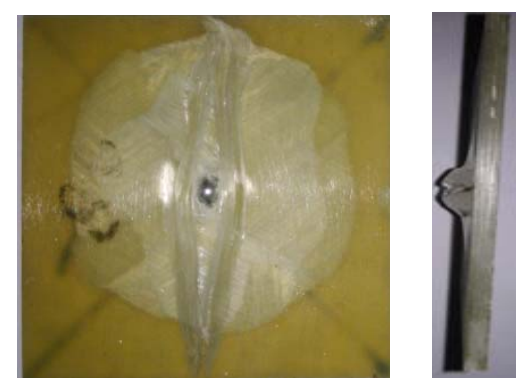

Bottom view Side view

Fig. 13. Laminates after indentation $\left(+/-45^{\circ}, 90^{\circ}\right)$

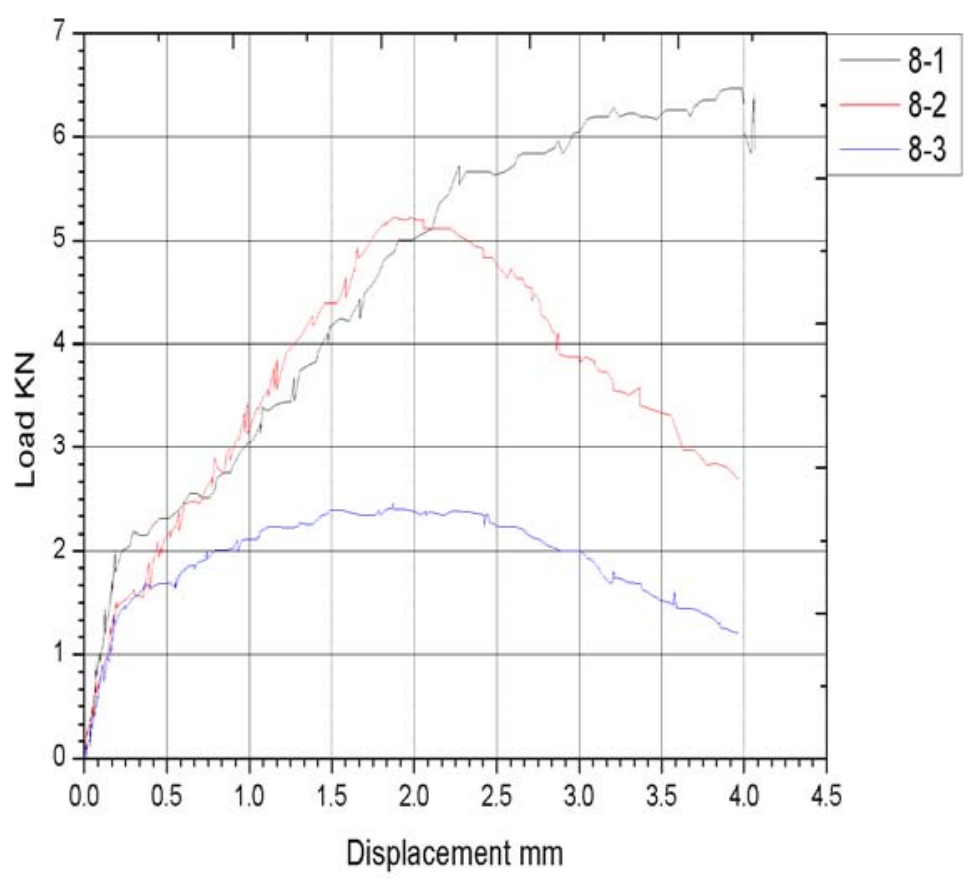

Fig. 14. Load vs. displacement (8-1 loading, 8-2 first reloading, 8-3 second reloading) 
From the beginning of the specimen loading, it is observed that laminate strength degraded. The load displacement was proportional (8-1 curve) up to a displacement of $0.25 \mathrm{~mm}$ with a load of $2 \mathrm{kN}$. The maximum load observed is $6.5 \mathrm{kN}$ at a displacement of $4 \mathrm{~mm}$. It is also observed that the damage was continuous, when the laminate was first time reloaded $(8-2$ curve), with the same stiffness (8-1 curve) with a load of $5.1 \mathrm{kN}$. For second reloading (8-3 curve) the maximum load of $2.4 \mathrm{KN}$ at an indenter displacement of $2.0 \mathrm{~mm}$ and gradual decrease in load up to an indenter displacement of $4.0 \mathrm{~mm}$ as shown in fig. 14.

\section{CONCLUSION}

The laminates have shown mixed results, that is some laminates have shown maximum load at the first loading itself and whereas other laminates shown maximum load at the second reloading which purely depend on the fiber orientation of the laminate. The laminates with fiber orientation $\left(0^{0} / 15^{0}\right),\left(0^{0} / 30^{0}\right),\left(0^{0} / 45^{0}\right)$ have shown maximum load at second reloading phase in a range of $4 \mathrm{kN}$ to $10 \mathrm{kN}$ at an indenter displacement of $4 \mathrm{~mm}$. The laminates with fiber orientation $\left(0^{0} / 60^{0}\right),\left(+/-45^{0} / 0^{0}\right),\left(+/-45^{0} / 90^{\circ}\right)$, have shown maximum load at first loading phase itself in a range of $6.5 \mathrm{kN}$ to $6.8 \mathrm{kN}$ at an indenter displacement of $4 \mathrm{~mm}$. The laminate with fiber orientation $\left(0^{0} / 90^{\circ}\right)$, have shown maximum load $6.8 \mathrm{kN}$ at second reloading phase at an indenter displacement of $4 \mathrm{~mm}$. Hence the laminate wit fiber orientation $\left(0^{0} / 30^{\circ}\right)$, has given a maximum load of $10 \mathrm{kN}$.

\section{ACKNOWLEDGEMENT}

The authors thank to CEO, Mr. Shravan and Principal, Dr. M. Venkataramana, of Vignan Institute of Technology \& Science, Deshmukhi, for providing necessary facilities at the college to complete this project work.

\section{REFERENCES}

1. Ross C.A., Sierakowski R.L., Studies on the impact resistance of Composite plates. Composites 4 (1973) 157-61.

2. Xiao J.R., Gama B.A., Gillespie Jr. J.W., Progressive damage and delamination in plain weave S-2 glass /SC-15 composites under quasi-static punch-shear loading. Composite struct., 78 (2007), 182-96.

3. AbiAbdallah, Christophe Bouvet. Experimental analysis of damage creation and permanent indentation on highly oriented plates, Composites science and Tech., 69, (2009), 1238-1245.

4. Crisfeld M.A., Mi Y, Davies Gao, Jellweg G.B., Finite element methods and the progressive failure modeling of composite structures. In Wen DRJ, et al., editor's .Computational plasticity fundamentals and applications, CIMNE Barcelona; (1997), 239-54.

5. Li CF. Hu N. Cheng JG. Fukumaga H. Sekine H. Low velocity impact induced damage of continuous fiber reinforced composite laminates. Part-II Compos part-A, 33 (2002), 1063-72. 
6. Mitrevski T. Marshall I.H., Thomson R., The influence of impactor shape on damage to composite laminates. Compos Struct., 76, (2006), 116-22.

7. Davies G.A.O., Zhang X., Impact damage prediction in carbon composite structures. Int. J. impact Eng., 16(1) (1995), 149-70.

8. Caprino G., Lopresto V., The significance of indentation in the inspection of carbon fibre reinforced plastic panels damaged by low-velocity impact. Compos. Sci. Technol., 60 (2000), 1003-12.

9. Caprino G., Lopresto V., Factors affecting the penetration energy of glass fiber reinforced plastics subjected to a concentrated transverse load. Proc. ECCM9, Brighton, UK; 4-7 June 2000

10. Caprino G., Lopresto V., The Penetration energy of fiber reinforced plastics under low-velocity impact conditions. Compos. Sci.Technol., 61 (2000), 65-73.

11. Freitas M., Silva A., Reis L., Numerical evaluation of failure mechanisms on composite specimens subjected to impact loading. Composite part B, 31 (3) (2000), 199-207.

12. Richardson M.O.W., Wiheart M.J., Review of low velocity impact properties of composite materials Composites, Part A -Appl, Sci. Manuf., 27A (12) (1996), 1123-31.

13. Wu E., Chang I.C., Woven glass/epoxy laminates subject to projectile impact, Int. J Impact Eng. 16 (4) (1995), 607-19.

14. Zhou G., Greaves I.J., Impact behavior of fiber reinforced composite materials and structures, CRC press, woodhead pubs., 2000, 133-185. 